\title{
EDITORIALS
}

\section{Communication and Behavior Change Challenges to Limiting the Development of Antibiotic Resistance}

\author{
Timothy Edgar, PhD \\ Department of Communication Sciences and Disorders, Emerson College, Boston, MA, USA.
}

J Gen Intern Med 27(7):758-9

DOI: $10.1007 / \mathrm{s} 11606-012-2000-1$

(c) Society of General Internal Medicine 2012

\begin{abstract}
A s any healthcare provider or health communication practitioner is well aware, effecting change in health behaviors is rarely a simple feat, but some forms of behavior change present much greater obstacles to success than others. In this issue of JGIM, Brookes-Howell and colleagues provide stimulating conceptual and methodological insights into lay interpretations of antibiotic resistance. ${ }^{1}$ However, from the perspective of an interventionist, the findings suggest that the communication challenges are daunting and will require innovative strategies for sustained behavior change to make a significant dent in this pressing public health threat. I have spent some time thinking about this problem, ${ }^{2}$ and this new evidence underscores how tough of a behavioral puzzle this is to solve. Antibiotic resistance is a very complex issue, because in order for the threat to subside, behavioral adherence is needed on the part of two distinct populations. First, providers themselves have an obligation to prescribe antibiotics in a prudent manner as well as effectively communicate to patients the appropriate way to use the medications. Second, patients have an equally key role to play by engaging in a series of behaviors that in the minds of consumers might not necessarily be linked (e.g., not demanding antibiotics from a physician, not hoarding or sharing antibiotics with others, washing hands properly). Because Brookes-Howell et al. focused their inquiry on the latter group, ${ }^{1}$ I will limit my comments to the patient side of the fence as well.

The approach taken by the British-Belgian team reflects a wise methodological choice, because the use of in-depth interviews permits us to penetrate the thoughts of the average citizen more deeply. Quantitative survey data serve an important function in assessing any health issue, but to really know the hearts and minds of the public, we need to hear the voices of people articulating their own thought processes. The voices in this case tell us that misunderstanding about antibiotic resistance abounds. The narratives show that multiple interpretations exist and that few of those interpretations reflect a clear understanding of what happens when
\end{abstract}

Published online February 3, 2012 antibiotic resistance occurs. Although the microbes themselves become resistant to a therapeutic agent, many see their own bodies as the source of resistance. People rely heavily on a common sense approach to why disease occurs and why potential cures might or might not work. ${ }^{3}$ If a drug appears not to have the desired effect in treating sickness, then the easiest way to account for the lack of efficacy of the medicine is either to place blame on the potency of the pharmaceutical itself or to see one's own body as the culprit. The Brookes-Howell et al. data tell us that the explanation for many resides within the body. That is, the most common lay conceptualization offered by study respondents in explaining antibiotic resistance was to say that their own bodies become resistant or are "getting used to" to antibiotics. ${ }^{1}$ Further qualitative work like that conducted by Brookes-Howell and her colleagues is needed to probe more deeply the sense-making process that consumers use to reach these conclusions so that communication initiatives can more effectively counteract flawed assumptions

The job of communicating effectively to the public about antibiotic resistance has not been made any easier by language choices imposed by the scientific community, especially the everyday label used for the phenomenon. As Brookes-Howell et al. observe "the phrase [antibiotic resistance] itself makes no mention of its subject." ${ }^{1}$ When Juliet asked "What's in a name?," she bemoaned the power of semantics in human perception, but the mighty influence of language cannot be denied for even a two-word brand as simple as "antibiotic resistance." On its face, the term implies that it is the drugs and not the bacteria that become resistant. To move toward a perceptual shift, I recommend that scientists think carefully about creating and spreading the use of an alternative expression that provides a clearer understanding of the biological mechanism at work. Certainly there is historical precedent for label transformation resulting in more favorable and accurate understanding of health issues such as moving from gay-related immune deficiency (GRID) to AIDS or talking about bipolar disorder instead of manic depression. Even if there were a clear and accurate understanding of the biological mechanism of antibiotic resistance across populations, communication professionals still face the challenge of personal identification. Well-established models of behavior change such as the Health Belief Model ${ }^{4}$ tell us that before any 
change occurs that individuals must believe that there is a reasonable probability that they themselves are susceptible to negative consequences, and they must also view a projected outcome associated with lack of behavior change as sufficiently severe to affect a person's life in unpleasant ways. With antibiotic resistance, both susceptibility and severity can be very difficult to grasp. To see oneself as susceptible, one has to believe that there is a high likelihood that the imprudent use of antibiotics will lead to unwanted negative health outcomes for self or for loved ones, but what is the evidence we see for that in our everyday realities? We might hear about people, for instance, who die from an uncontrolled bacterial infection, but rarely is the link made either through mediated messages or life experience that inappropriate use of antibiotics is the primary culprit.

Another major communication challenge the scientific community faces in making a significant dent with the antibiotic resistance problem is that behavior change, especially on the part of the patient community, comes with minimal tangible immediate rewards, and the longterm rewards too easily can be elusive and difficult to comprehend. Some frequently used frameworks for behavior change begin with an assumption that "we are needdirected beings with a natural inclination to try and improve our lot," ${ }^{5}$ and it is always more satisfying to improve one's own lot right away rather than waiting for the promise of good things to come years in the future. If one begins and maintains a new program of regular cardiovascular exercise, the person is likely to notice a shrinking waistline within a matter of weeks. However, if we try to persuade individuals not to demand that their internists call in an antibiotic prescription for a common cold, what is the payoff for refraining? Following guidelines for the prudent use of antibiotics for the consumer does have a potential payoff for a population as a whole over time, but personal rewards are tough to identify beyond the pleasure of an altruistic feeling for doing something good for the whole of society. Unfortunately, altruism has its limits when it comes to rewarding sustainable behavior. The challenge is not unlike the one faced by those who wish to improve the environment by reducing individual carbon footprints. We have made strides in that arena, but we still have a long way to go, because individuals who engage in pro-environmental actions rarely experience any short-term rewards beyond a warm feeling of saving the planet for the future. In some ways, those engaged in the fight against antibiotic resistance face even greater challenges. If you want me to throw my used plastic bottle into a recycle container, that action typically happens during an unremarkable moment in one's life. If you want me not to ask my internist for an antibiotic for flu symptoms the day before I deliver an important presentation to clients at work, you are asking me to do so in a moment when I am stressed and my first priority is to get a promotion rather than doing my share to contribute to the overall betterment of health for society. It is much easier to insist vehemently that an antibiotic be prescribed rather than to take the time to listen to the physician's explanation for why an antibiotic will not cure a viral infection.

I do not wish to convey a doomsayer tone, because there is evidence that carefully planned initiatives can make a difference in behavior, ${ }^{6}$ and I am optimistic that we can successfully combat this problem with innovative strategies and tactics. For example, relying on principles of social marketing, which mirrors an approach to behavior change used by commercial marketers, provides the medical community with a multi-pronged approach that goes beyond simple messaging and offers guidance on how to restructure the environment in which health-related decisions get made. ${ }^{2}$ We also need to look beyond traditional channels of communication and examine how social media tools such as Facebook, Twitter, and blogging can be integrated into a comprehensive strategy for change. ${ }^{7}$ I strongly believe we will be able to claim victory in the long run if we take a careful look at the barriers that lie ahead and construct effective approaches to overcome the obstacles.

Corresponding Author: Timothy Edgar, PhD; Department of Communication Sciences and Disorders, Emerson College, 120 Boylston Street, Boston, MA 02116, USA (e-mail: timothy_edgar@emerson.edu).

\section{REFERENCES}

1. Brookes-Howell L, Elwyn G, Hood K, Wood F, Cooper L, Goossens H, Ieven M, Butler CC. "The body gets used to them:" Patients' interpretations of antibiotic resistance for containment strategies. J Gen Intern Med. 2012; doi:10.1007/s11606-011-1916-1.

2. Edgar T, Boyd S, Palamé M. Sustainability for behaviour change in the fight against antibiotic resistance: A social marketing framework. J Antimicrobial Chemother. 2009;63:230-237.

3. Moscovici S, Duveen G. Social representations: Explorations in social psychology. Cambridge, UK: Polity; 2000.

4. Rosenstock IM, Strecher VJ, Becker MH. Social learning theory and the health belief model. Health Educ Behav. 1988;38:175-183.

5. Hastings G, Saren M. The critical contribution of social marketing. Marketing Theory. 2003;3:305-322.

6. Huttner B, Goosens H, Verheij T, Harbarth S. on behalf of the CHAMP consortium. Lancet Infect Dis. 2010;10:17-31.

7. Chou WS, Hunt YM, Beckjord EB, Moser RP, Hesse BW. Social media use in the United States: Implications for health communication. J Med Internet Res. 2009;11(4):e48. 